\title{
Exploring the Impact of Destination Health Risk Image on Post Covid-19 Travel Behavior
}

\author{
Samarasinghe GDRS*, Bombuwala BDDM**, Jayarathne EHRS***, Jayaruwan EGAPB****, Kuruppu CL***** \\ Karunarathna KNP*******
}

${ }^{*}$ SLIIT Business School, Sri Lanka Institute of Information Technology

DOI: 10.29322/IJSRP.11.12.2021.p12012

http://dx.doi.org/10.29322/IJSRP.11.12.2021.p12012

\begin{abstract}
From its inception, Sri Lanka commenced strong precautions to prevent the spreading of the virus, which helped to mitigate its impact. Even though the overall damage was initially minor, travel and tourism, the country's third-largest income source, has plummeted due to the fear of traveling and the need to maintain social distance. Before conducting the study, the researchers distributed a questionnaire to detect any problem with passengers' perceptions of destination health risks. The conceptualization framework of the study is designed to identify the relationship between independent and dependent variables, which describe the relationship between the destination health risk image and travelers' behavior. This unexpected public health disaster has now turned into a devastating economic crisis for the entire world, including the tourism, hotel, and event industry. In tandem with the recovery of other sectors, the recovery must gradually counteract the outbreak and restore economic performance.
\end{abstract}

Keywords- Perceived severity of health-related risk, Perceived probability of health-related risk, Travelers' Behavior

\section{INTRODUCTION}

Coronavirus disease 2019 (COVID-19) has ravaged the globe, killing millions of people, shutting down economies, closing borders, and spreading misery on a global scale. It has pushed healthcare systems and staff to breaking point in many areas, and it will undoubtedly have a long-term impact on medical research. The COVID-19 pandemic is spreading across the world at an exponential rate. Researchers, technologists, doctors, and other healthcare professionals work around the clock to create vaccines and treatments to combat and treat the virus. With exponentially growing illnesses, both affluent and developing countries are reporting corresponding fatalities. As of today, more than one million people have been infected with the virus worldwide. Uncertainty has beset various sectors since the establishment of COVID-19 in the latter part of 2019, particularly affecting the tourist and hotel industries. As an industry based on close contact and human mobility, the hotel and tourism industry is both a co-creator and a primary recipient of the epidemic and its consequences.

The COVID-19 response and recovery actions of governments, organizations, enterprises, and individuals have been driven and influenced by the economic structure and mentality that contributed to COVID-19. Because we are treating the symptoms rather than the causes, this has the potential to prolong and repeat crises substantially.

As a result of the pandemic crisis, people's behaviors are changing, and passenger behavior should be monitored and identified to develop strategies. Changes may occur during the destination selection phase, the transport mode selection phase, and the information search phase. Purchasing power, health and safety in terms of sanitation and cleanliness, insurance policies, and the knowledge are the factors that drive these changes. Significant changes will occur in post-pandemic travel planning and tourist behavior, particularly in how people assess and perceive their exposure to the numerous threats offered.

Tourists rely on destination photographs to convey the physical attributes of a location. The destination image is used to deal with diverse perceived threats. One of the essential elements to consider in pandemic circumstances is the health risk. The greater the health risk associated with a trip, the greater the destination's perceived danger. Tourists' travel avoidance behavior shows that they may build a negative image due to the heightened perceived health risk.

Furthermore, this study found a need to understand the perceived danger and its possible impact on destination image that could influence visitor behavior intentions. COVID-19 enforces social separation by limiting social contact, avoiding crowded settings, and limiting travel. Social distance influences people's perceptions and assessments of leisure and vacation activities, including hiking, outdoor activities, and nature-based tourism, as well as personal services like spas, dining, and concierge services. The sceneries and attractions that a country has to offer have significant differences. As a result, a trip to Sri Lanka will benefit visitors with a wide range of travel interests. It is a vital supporter of island economies and one of the most important companies in the Sri Lankan economy, generating much-needed foreign currency. Scholars could not find empirical studies on the "Impact of Destination Health Risk Image on Post COVID-19 Travel Behavior," which results in an empirical gap between the two fields of study.

\section{LITRITURE REVIEW}

Impact of the Pandemic: According to World Health Organization, the impact on human health has been the most 
evident and destructive of all the consequences of coronavirus disease in 2019 [1]. On the other hand, the pandemic's growing economic devastation distinguishes it from any previous recent calamity. COVID-19 has a massive impact on the world's economic, political, and social institutions. The health communication methods and actions have influenced global travel, tourism, and enjoyment (e.g., social distance, travel and mobility bans, community lockdowns, remain at home campaigns, self- or mandatory quarantine, and crowding restrictions). On the other hand, the nature, circumstances, and repercussions of the COVID-19 suggest that this crisis is not only exceptional but also has the potential to have strong and long-term structural and transformative effects in tourism as a socio-economic activity and enterprise. Globally and regionally, the COVID-19 pandemic has had a substantial influence on most industries. Since the virus's first appearance in China, more than a hundred million cases have been reported in 223 nations, areas, or territories, with a cumulative death toll of 2,703,620 as of March 21, 2021 [1].

"Coronavirus is harming the world more than World War II" and global tourism is undergoing its worst crisis since the onset of modern travel in the last century [2]. Tourism and hospitality are among the most affected by COVID-19 health pandemic and economic repercussions due to a multitude of interconnected factors, including travel restrictions, national lockdowns, business closures, and the subsequent impact on tourism and hospitality industries.

COVID-19, a pneumonic disease, will have overrun the entire world in a pandemic [3]. The World Health Organization designated it a pandemic on March 11, 2020, claiming travel and mobility as factors in its rapid worldwide spread, the unavailability of a vaccine, and soaring cases and deaths. Pandemics in the past have not caused such damage to the global economy. Travel restrictions and country-wide lockdowns were imposed due to the exceptional health situation affecting the tourism industry, which relies heavily on human mobility [4].

Perceived Severity of Health-Related Risks: The perceived health behavior change theories using health-related risk severity as a significant factor [5]. According to the research study, disease risk perception is an important aspect of health behavior. People's health and safety risk perceptions can directly impact their decisions and actions [6]. Perceived severity stressed an individual's relevant awareness of how the progress of the disease may be essential for them. During the epidemic, people were terrified of contacting the outside world due to a high perceived level of COVID-19, resulting in little acts that individuals could manage. People were more prone to feel bored, irritable, and anxious after months of low-level stimulation [7]. If a health problem has less chance of developing, no action should be taken to prevent it, irrespective of its severity [8].

"Risk Perception and Health Behavior" was the research [9]. Accordingly, many health behavior change theories include risk perceptions or an individual's seeming sensitivity to risk. Risk perceptions are frequently targeted in health behavior modification programs, and new meta-analytic research suggests that treatments that effectively engage and modify risk beliefs result in successful increases in health behaviors. The current literature on risk perceptions and health behavior is reviewed here, including investigations on risk perception formation, types of risk perceptions (affective, deliberative, and experiential), risk perception accuracy, and interactions and associations among types of risk perceptions. The existing research suggests that illness risk perception is a substantial predictor of health behavior, albeit the connection between risk perceptions and health behavior may vary depending on the profile of various forms of risk perceptions and their accuracy.

According to existing nomenclature and theory, risk reasoning is the substance of risk reasoning as opposed to the derived reasoning process [10]. As a result, people will be able to access information intentionally. For instance, a patient may be aware that her perception indicates that she is vulnerable to COVID-19, even though she has no direct connection to the courses that contributed to the formulation of that judgment. Such risk perceptions include vulnerability assessments, such as asking, "How vulnerable do you feel?" or risk gist-representations [5]. In general, known risk perceptions predict intentions more accurately than planned risk perceptions.

Perceived Probability of Health-Related Risks: Perceived severity and perceived probability are linked but distinct concepts that work together to form health-related risk and influence health behavior [11]. If someone believes there is no chance of a health problem, they should not be interested in taking steps to prevent it [8]. The term "perceived probability" refers to a person's subjective assessment of their own risk of spreading the disease. Although perceived severity and perceived probability are related, they are two distinct ideas. On the other hand, experimental psychology research [11] has suggested that greater apparent consequences of disease spread on others may enhance social isolation.

On the COVID-19 scale, it is unknown how perceived risk links to preventive behaviors in the early phases of a pandemic [12]. Even more, we are unaware of any such data for the present COVID-19 pandemic. Given COVID-19's continued expansion and the necessity to implement preventive behaviors at a population level, such data could be of worldwide significance for nations where the virus has not yet spread and for future pandemics. According to findings from a macro conducted [11], involvements that increase perceived probability significantly impact health-related risks and behaviors such as immunization, nutrition, fitness activity, and sun protection compared to interferences that only consider the perceived probability. Even though both risk features are essential in driving preventive action, much research focuses on susceptibility perceptions rather than severity views.

Travelers' Behavior: According to reports, the tourism industry needs to cope with crises occasionally because time is of the utmost importance and is influenced by external factors. Whether natural or man-made, the goal is to create an unhappy timeline in which a global crisis is always present. The COVID19 virus, released in 2019, was unstable globally. The current level of uncertainty about the epidemic's impact has shifted and been estimated - it is a long-term impact. Anxiety and other negative affective behavior are exacerbated by perceived danger, which may detrimentally impact a tourist's desire to travel [13]. The effect of COVID-19 on marketing is it reaches out to people and has a severe strong impact on tourist behavior where the people's culture differs from the setting.

COVID-19 has a destructive economic and psychological impact on travelers [14]. The findings revealed that the explosion 
was caused by Tourists' perceptions of emotions that had shifted negatively due to COVID-19. Insecurity, fear of danger, a lack of confidence, and unpleasantness have all contributed to a shift in visitor confidence in visitors. The fact that most tourists must travel after six months is the last evidence that the virus has struck. The post-epidemic tourist industry has claimed that destiny reputation image is a deciding element as a cognitive-based market.

"Post COVID-19 behavior" patterns [15]. The findings suggest that some efforts such as increasing supply and disinfecting vehicles result in a higher propensity to use public transportation during post-COVID-19 times. Similarly, requiring handlebar and steering wheel covers significantly enhances people's desire to use contribution services. However, respondents anticipate these steps and improvements will be implemented while keeping prices unchanged from pre-COVID-19 levels. The findings of this study could aid operators in developing methods to encourage users to accept and retain their services.

\section{RESEARCH METHODOLOGY}

The impact on human health was the most visible and harmful ramifications of the coronavirus disease in 2019 according to WHO, COVID-19 Impact [16]. The pandemic's escalating economic devastation, on the other hand, sets it apart from any other recent calamity. The COVID-19 pandemic has had a significant impact on most industries globally and regionally. Researchers selected the "Impact of Travel Behaviors owing to COVID-19" due to the pandemic situation. Selected a quantitative study based on previous research articles and information collected from travelers to Sri Lanka.

Conceptual Framework: The study's conceptualization framework is intended to reveal the relationship between independent and dependent variables that describe the relationship between the destination's health risk image and traveler behavior. According to the study, travelers' behavior is a dependent variable influenced by Perceived severity of health-related risk, and Perceived probability of health-related risk is an independent variable characterized under the destination health risk image. After evaluating the literature and prior studies, the researchers discovered specific relationships among the variables, which form the basis for this research issue [18]. In general, researchers have found two categories of factors and their relationships. The impact of destination health risk image on tourist behavior in the hotel sector in Sri Lanka is described in the research framework (Figure $1)$.

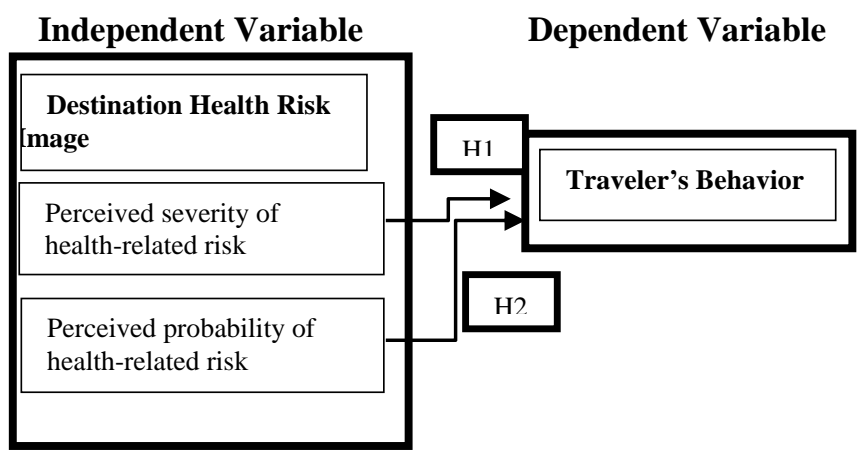

This publication is licensed under Creative Commons Attribution CC BY. http://dx.doi.org/10.29322/IJSRP.11.12.2021.p12012

\section{Figure 1: Conceptual framework}

The researchers selected positivism because they believed that consulting existing literature and hypotheses derived from current theories would get a general grasp of the impact of destination health risk image on visitor behavior in the Sri Lankan hotel industry [20]. Two techniques can be used in this study, in which both inductive and deductive procedures were used. Researchers employed a deductive technique to develop a theory and hypotheses and a research method to evaluate the hypotheses. The researchers employed a deductive approach as their research method because this study aims to evaluate hypotheses. Local and foreign visitors who traveled to Sri Lanka throughout the study period were the target population. Local and international travelers who stayed in hotels across Sri Lanka and hotel management provided information to the researchers. The simple random sampling approach was used to select samples at random from groups. This study gathered primary data from Sri Lankan and international visitors who stayed in the country.

Validity and Reliability: The reliability of the questionnaire was assessed by a reliability test (Table 1). Cronbach's alpha is a metric for internal consistency, or how closely a group of objects is related. A high alpha value is frequently used to demonstrate that the items measure an underlying component.

table 01 : Reliability Statistics
\begin{tabular}{l|l} 
Cronbach's Alpha & N of Items \\
\hline .877 & 16 \\
\hline
\end{tabular}

The term "validity" refers to determining what sort of measurement the research is truly designed for and the accuracy of the study's conclusions. The questionnaire was given to other research specialists to provide input on its sufficiency and representativeness to ensure that it included all variables studied, a procedure known as content validity. A high value of alpha is often used as evidence that the items measure an underlining construct. The reliability analysis procedure calculates several commonly used measures of scale reliability and provides information about the relationship between individual items in the scale. The test will be significant when the alpha value is above 0.6. According to the research the value is 0.877 and a strong reliability available in this study [17].

\section{DATA ANALYSIS}

Demographic Factors: Most respondents (55.6\%) were male and others were female respondents (44.4\%) were female. Most consumers were male, according to the data collected. Regarding the research topic, males have shown more travel behavior. With the collected data, 261 respondents $(87.9 \%)$ belonged to the 20-40 category, 22 respondents $(7.4 \%)$ belonged to the 40-60 category, and 14 respondents $(4.7 \%)$ were under age 20. Most respondents were from Asian countries. Asians love to visit Sri Lanka due to the beauty of the country, safety, hospitality, and economy at the time of the data collection.

象 
Most Asians have food flavors similar to Sri Lanka, which increases the Asians' attraction towards the country. Most respondents were single, i.e., 226 respondents $(76.1 \%)$ were single, and 71 respondents (23.9\%) were married. One-hundredtwo respondents (34.34\%) have visited for adventurous purposes, and 104 respondents (35.01\%) visited Sri Lanka for family vacations. According to the collected data, 34 respondents (11.4\%) have visited for business purposes.

Out of 297 respondents, 28 respondents $(9.42 \%)$ visited Sri Lanka for spiritual purposes, and 29 respondents $(9.76 \%)$ visited for religious purposes. 39\% of travelers (115 respondents) in this sample came to Sri Lanka to visit mainly Hill stations, while 30\% ( 90 respondents) of travelers visited beach areas around the island. These findings indicate that the remaining 19\% (55 respondents) and $12 \%$ (37 respondents) of travelers in this sample came to Sri Lanka to visit due to religious places and historically significant sites.

Analyzing the accommodation locations of travelers' in this sample revealed that the majority, i.e., $43 \%$ (129 respondents) of all travelers in the sample, can afford to stay at resorts, while the next 35\% (104 respondents) can afford economical hotels. Only five respondents have stayed in luxury apartments (with over five floors) during their stay in Sri Lanka in this pandemic situation.

Descriptive Statistics: Descriptive statistics helped to summarize and present this data in a meaningful manner to facilitate understanding the underlying information. Descriptive statistics are numerical and graphical methods that summarize data and bring forth the underlying information. The numerical methods include measures of central tendency and measures of variability. The means are determined by using a five-point Likert scale, rating from (5) Not at all, (4) No, (3) Not Sure, (2) Yes, and (1) Definitely.

Table 02: Descriptive Analysis for the Perceived Severity

\begin{tabular}{|l|l|l|l|}
\hline Factor & Mean & Correlation & SD \\
\hline $\begin{array}{l}\text { Do you feel that the } \\
\text { probability of you getting } \\
\text { infected with Covid-? }\end{array}$ & 4.53 & 0.586 & 0.861 \\
\hline $\begin{array}{l}\text { Do you think that } \\
\text { travelling is risky during } \\
\text { this pandemic? }\end{array}$ & 4.25 & 0.793 & 0.856 \\
\hline $\begin{array}{l}\text { Do you think that hotels } \\
\text { are taking adequate } \\
\text { preventive measures to } \\
\text { ensure the safety of } \\
\text { visitors from Covid-19? }\end{array}$ & 4.23 & 0.766 & 0.822 \\
\hline $\begin{array}{l}\text { Do you think that you will } \\
\text { be served well and face no } \\
\text { trouble if you travel }\end{array}$ & 4.15 & 0.508 & 0.782 \\
\hline
\end{tabular}

\begin{tabular}{|l|l|l|l|}
\hline $\begin{array}{l}\text { during this period to Sri } \\
\text { Lanka? }\end{array}$ & & & \\
\hline
\end{tabular}

As per Table 2, analyzed data reveal that respondents have a 4.33 Mean value. Most respondents have agreed that COVID-19 has affected many aspects, denoting the respondents have a clear idea about the pandemic situation and are aware of the risk. Out of the total respondents, most have agreed that they need the Covid vaccine for further safety. Respondents have given priority to COVID-19 preventive measures with the day-to-day needs. The mean value signifies that most respondents have adequate confidence in COVID-19 preventive measures.

According to the collected data, most respondents are aware of the COVID-19 threat and have followed the safety measures for the pandemic. Most respondents highly agreed that safety measures must be followed to escape from the pandemic situation.

\section{Table 03: Descriptive Analysis for Perceived Probability}

\begin{tabular}{|l|l|l|l|}
\hline Factor & Mean & Correlation & SD \\
\hline $\begin{array}{l}\text { Do you feel that the } \\
\text { probability of you getting } \\
\text { infected with Covid-? }\end{array}$ & 4.53 & 0.586 & 0.861 \\
\hline $\begin{array}{l}\text { Do you think that travelling } \\
\text { is risky during this } \\
\text { pandemic? }\end{array}$ & 4.25 & 0.793 & 0.856 \\
\hline $\begin{array}{l}\text { Do you think that hotels are } \\
\text { taking adequate preventive } \\
\text { measures to ensure the safety } \\
\text { of visitors from Covid-19? }\end{array}$ & 4.23 & 0.766 & 0.822 \\
\hline $\begin{array}{l}\text { Do you think that you will be } \\
\text { served well and face no } \\
\text { trouble if you travel during } \\
\text { this period to Sri Lanka? }\end{array}$ & 4.15 & 0.508 & 0.782 \\
\hline
\end{tabular}

According to the analyzed data in Table 3 , most travelers believed that there is a high risk of being infected with COVID-19 during traveling. The mean value of 4.25 suggested that most respondents believed traveling was risky during the pandemic. The respondents also believed that hotels ensure travelers' safety within the prevailing pandemic situation. According to the collected data, respondents believed the condition of Sri Lanka is safe for travel (at the time of data collection).

During the data collection period, most respondents believed that Sri Lanka has a safe environment for traveling. Many respondents have followed the safety precautions provided. The collected data revealed that respondents had good knowledge 
about the pandemic situation and had observed the safety precautions well.

Correlation Analysis: Correlation is a statistical analysis that determines and analyzes the degree to which two variables vary in relation to one another. Pearson Correlation Analysis is the most often used analysis method in this area. This section attempts to determine if a hypothesis is accepted or rejected.

A correlation analysis is used to determine the statistical link between measurement variables and quantify the strength of the impact of the independent variable on the dependent variable. The analysis results show (Table 4) that the following have statistically significant (p 0.05) relationships.

\section{Table 04: Correlation between Perceived Severity Health-}

\section{Related Risk and Travelers' Behavior}

\begin{tabular}{|c|c|c|}
\hline & $\begin{array}{l}\text { Perceived } \\
\text { Severity } \\
\text { Health } \\
\text { Related } \\
\text { Risk } \\
\end{array}$ & $\begin{array}{l}\text { Travelers } \\
\text { Behavior }\end{array}$ \\
\hline $\begin{array}{l}\text { Pearson } \\
\text { Correlation }\end{array}$ & 1 & $.776^{* *}$ \\
\hline Sig. (2-tailed) & & .000 \\
\hline $\mathrm{N}$ & 297 & 297 \\
\hline $\begin{array}{l}\text { Pearson } \\
\text { Correlation }\end{array}$ & $.776^{* *}$ & 1 \\
\hline Sig. (2-tailed) & .000 & \\
\hline $\mathrm{N}$ & 297 & 297 \\
\hline
\end{tabular}

The researchers proved a positive relationship between Perceived Severity Health-Related Risk and Travelers' Behavior of the sample. The correlation coefficient was 0.776 , which is statistically significant at the 0.01 level. Furthermore, these two variables have a considerable relationship, backed up by the fact that significance has a zero value.

It implies that "Perceived Severity Health-Related Risk and Travelers' Behavior" have a positive relationship. The collected data indicate that most respondents have accepted Perceived Severity Health-Related Risk. With the result, "H1: There is a relationship between perceived severity and travelers' behavior in the hotel industry in Sri Lanka," was accepted.
Table 05: Correlation between Perceived Probability of

\section{Health-Related Risk and Travelers' Behavior}

\begin{tabular}{|c|c|c|}
\hline & $\begin{array}{l}\text { Perceived } \\
\text { Probability of } \\
\text { Health } \\
\text { Related Risk }\end{array}$ & $\begin{array}{l}\text { Travelers } \\
\text { Behavior }\end{array}$ \\
\hline Pearson Correlation & 1 & $.880^{* *}$ \\
\hline Sig. (2-tailed) & & .000 \\
\hline $\mathrm{N}$ & 297 & 297 \\
\hline Pearson Correlation & $.880^{* *}$ & 1 \\
\hline Sig. (2-tailed) & .000 & \\
\hline $\mathrm{N}$ & 297 & 297 \\
\hline
\end{tabular}

At the 0.01 level, the correlation coefficient was 0.880 , which is statistically significant. Furthermore, there is a significant link between these two variables. The fact that significance has a zero value backs this up. It implies a positive relationship between "Perceived Probability of Health-Related Risk and Travelers' Behavior." The majority of respondents agreed on Perceived Probability of Health-Related Risk based on the provided facts. Furthermore, regarding the results, " $\mathrm{H} 2$ : There is a relationship between perceived probability and travelers' behavior in the hotel industry in Sri Lanka" was accepted.

Table 06: Analysis of Variance (ANOVA) for Multiple Linear Regression

\begin{tabular}{|c|c|c|c|c|c|c|}
\hline \multicolumn{2}{|c|}{ Model } & $\begin{array}{l}\text { Sum of } \\
\text { Squares }\end{array}$ & df & $\begin{array}{l}\text { Mean } \\
\text { Square }\end{array}$ & $\mathrm{F}$ & Sig. \\
\hline \multirow[t]{3}{*}{1} & $\begin{array}{l}\text { Regress } \\
\text { ion }\end{array}$ & 140.228 & 4 & 35.057 & $\begin{array}{r}460.4 \\
38 \\
\end{array}$ & $.000^{\mathrm{b}}$ \\
\hline & $\begin{array}{l}\text { Residua } \\
1\end{array}$ & 22.232 & 292 & .076 & & \\
\hline & Total & 162.460 & 296 & & & \\
\hline
\end{tabular}

a. Dependent Variable: Travelers Behavior

b. Predictors: (Constant), Perceived Response Efficacy,

Perceived Severity Health Related Risk, Perceived Self

Efficacy, Perceived Probability of Health-Related Risk

Table 6 reveals that out of 162.460 total sums of squares, 140.228 of variation could be explained by the regression, and 22.232 of variation of dependent variable "Traveler's Behavior" 
is explained by residual. Because regression contributes to a major amount of the model, it can be concluded that it fitted well. It is worth noting that the $\mathrm{F}$ value is 460.438 . Because the calculated $\mathrm{F}$ value is larger than the Table $\mathrm{F}$ value, it implies that the model explains most of the variation. The P-value of 0.000 , which is less than 0.05 , indicates that the model can predict the dependent variable "Travelers' Behavior" as statistically significant.

\section{DISCUSSION AND CONCLUSION}

Contribution of the Study: Visitors, their loved ones, and/or others have reported significant disruptions and health difficulties in travel and booking arrangements (e.g., usergenerated content). Tourists throughout the world are hesitant to travel due to health concerns. Traveler behavior is influenced by the perceived health risk associated with the destination image. In the future, these changes may have a positive or negative impact on the tourism and hotel businesses. Maintaining a watchful eye on those habits is vital since fresh opportunities or potential threats can be detected and mitigated by suggesting suitable actions. Most operations, for example, are now handled virtually, and the tourism business uses digital platforms to provide information to travelers. Information is crucial in this pandemic situation since passengers are strongly reliant on it.

Early on, Sri Lanka took vigorous measures to prevent the virus from spreading, which reduced the effect. Even though the overall impact was minimal at first, travel and tourism, the country's third-largest source of foreign currency, have plunged due to the dread of traveling and the desire to preserve social distance. Safety is one of the most crucial features for a tourist. Because each destination's health risk is unique, it is vital to maintain visitor safety in the future based on the health risk associated with that location. The current passenger behavior will be studied to provide insight into the industry's future operations. Discussion: The tourism and hospitality industries will undergo significant changes in the coming months. As a result of increased global and local demand to improve health standards, all tourism and hospitality service providers will have to react with improved disease prevention and control strategies for the health and safety of both in-house visitors and personnel. During the check-in procedure, all hotels will make it essential for guests to bring updated health reports. Furthermore, prior to making a reservation, guests will pay more attention to the hotel's safety requirements, and online travel review services will begin assigning space to grade hotel safety standards. The health safety of crowded public facilities, such as terminals, restaurants, lobby areas, swimming pools, restrooms, lounges, and bedrooms, will receive special attention. Smart hotels will be forced to deliver contactless room service with robot waiters, upending the tourism and hospitality industry's traditional beginnings.

The sample's Perceived Severity Health-Related Risk and Travelers' Behavior have a favorable association. At the 0.01 level, the correlation coefficient was 0.776 , which is statistically significant. Furthermore, there is a significant link between these two variables. The fact that significance has a zero value backs this up. It implies a favorable association between "Perceived Severity Health-Related Risk and Travelers Behavior." The majority of respondents acknowledged Perceived Severity Health-Related Risk based on the provided facts.

The correlation coefficient was 0.880 at the 0.01 level, which is statistically significant. These two variables have a considerable relationship. This is supported by the fact that significance has a value of zero. It implies that "Perceived Probability of HealthRelated Risk and Travelers' Behavior" has a positive association. Based on the data supplied, the majority of respondents agreed on the Perceived Probability of Health-Related Risk.

Conclusion: Since tourism is one of the world's largest and fastest-growing businesses, it is projected to play a key part in recovering of socioeconomic stability following the COVID-19 pandemic. It is a major contributor to the island economies and one of the most vital sectors in the country, generating muchneeded foreign currency. The island's long-suffering tourism business was most recently impacted hard by the Easter bombings, which occurred in several locations throughout the country, including luxury hotels.

As a country with limited resources, including strategic initiatives to mitigate the economic downturn is critical. In this setting, travel and tourism, the country's third-largest source of foreign cash, has completely collapsed due to the fear of traveling and the necessity to maintain social distance.

Tourist arrival at a destination is heavily influenced by two factors: Perceived severity of health-related risk and Perceived probability of health-related risk. The COVID-19 has significantly impacted all these factors, reducing international visitor arrivals to levels never experienced before. For example, in the current pandemic scenario in our 'Top 10' source markets, the majority were severely impacted by COVID-19 in terms of virus spread and mortality rate. Furthermore, it is critical and will play a key part in the global economic recovery following COVID-19. As a result, virtual and hybrid events emerge as two more possibilities to explore in the face of disruption, with various advantages, including greater financial rewards, improved attendance, measurability, and ease of transition.

\section{REFERENCE}

[1] Abdullah, M., Charitha Dias, Deepthi Muley, Shahin M D,. Exploring the impacts of COVID-19 on travel behavior and mode preferences. Transport. Res. Interdiscipl. Perspect, 2020, 1-13

[2] Akhoondnejad, A., . Analyzing the pretravel, on-travel, and post-travel behaviors of Iran's firsttime visitors. Journal of Travel \& Tourism Marketing, 2015, Volume 32(8), 15-25

[3] Arimura, M., Tran V H., Okumura, K., Asada, T., Changes in urban mobility in Sapporo City, Japan due to the COVID-19 emergency declaration. Transp. Res. Interdiscip. Perspect,2020,7, 1-14

[4] Awad-Núñez, S. J., et al,. Post-COVID-19 travel behaviour patterns: impact on the willingness to pay of users of public transport and shared mobility services in Spain. European Transport Research Review, 2021, 13(20), pp. 1-18.

[5] Birhanu, Z. A.,. Risk perceptions and attitudinal responses to COVID-19 pandemic: an online survey in Ethiopia. BMC public health, 2021 Volume 21 , pp. 1-17. 
[6] Budd, L.,. Responsible transport: A postCOVID agenda for transport policy and practice. Transport. Res. Interdiscip. Perspect,2020

[7] Chebli, A.,. The Impact of Covid-19 on Tourist Consumption Behaviour : A Perspective Article. Journal of Tourism Management Research, 2020 Volume 7(2), pp. 196-207.

[8] Chien, P. S.,. Travelers' health risk perceptions and protective behavior: A psychological approach. Journal of Travel Research, Volume 56(6), pp. 744-759.

[9] Chinazzi, M.,. The effect of travel restrictions on the spread of the 2019 novel coronavirus (COVID-19) outbreak. Journal of Science, 2021

[10] Cummings, M., 2020. Survey shows pandemic's severe impact on U.S. Small businesses. Yale News, 2020

[11] GösslingPandemics, tourism and globa Ichange :A rapid assessment of COVID-19. Journal of Sustainable Tourism, pp. 2020, 1-20.

[12] Haas, M.,. How COVID-19 and the Dutch 'intelligent lockdown' change activities, work, and travel behavior: Evidence from longitudinal data in the Netherlands. Transp. Res. Interdiscip. Persp, 2020

[13] Hotle, S.,. Influenza risk perception and travel-related health protection behavior in the US: Insights for the aftermath of the COVID-19 outbreak. Transport. Res. Interdiscip. Perspect, 2020

[14] Kim, M.,. What influences COVID-19 biosecurity behaviour. Current Issues in Tourism, Volume 1, pp. 1-10, 2021.

[15] Kovačić, S. M.,. What are the Factors affecting Tourist Behavior based on the Perception of Risk? Romanian and Serbian Tourists'
Perspective in the Aftermath of the recent Floods and Wildfires in Greece. Sustainability, 2020 Volume 12, pp. 12-63.

[16] Liao, C. Y.,. Perceived Knowledge, Coping Efficacy and Consumer Consumption Changes in Response to Food Recall. MDPI, 2020.

[17] Nuskiya, M. H. F.,. Covid-19 crisis and recovery of hotel industry: a strategic focus on tourism sector in sri lanka. International Tourism Research Conference, 2020, Volume 4, pp. 50-59.

[18] Parady, G.,. Travel behavior changes during the COVID-9 pandemic in Japan: Analyzing the effects of risk perception and social influence on going-out self-restriction. Transp. Persp. Interdiscip. Persp, 2021.

[19] Samarathunga, W.,. Post-COVID19 Challenges and Way Forward for Sri Lanka Tourism. SSRN Electronic Journal, 2021.

[20] Shashiripour,. How is COVID-19 reshaping activity-travel behavior? Evidence from a comprehensive survey in Chicago. Transportation Research Interdisciplinary Perspectives, 2021.

\section{AUTHORS}

First Author - Author name, qualifications, associated institute (if any) and email address.

Second Author - Author name, qualifications, associated institute (if any) and email address.

Third Author - Author name, qualifications, associated institute (if any) and email address.

Correspondence Author - Author name, email address, alternate email address (if any), contact number. 